\title{
Non-dissipative internal optical filtering with solution- grown perovskite single crystals for full-colour imaging
}

\begin{abstract}
Sergii Yakunin ${ }^{1,2}$, Yevhen Shynkarenko ${ }^{1,3}$, Dmitry N Dirin ${ }^{1,2}$, Ihor Cherniukh ${ }^{1,2}$ and Maksym V Kovalenko ${ }^{1,2}$
Herein we demonstrate that solution-grown single crystals of semiconducting methylammonium lead halide perovskites (MAPbX where $\mathrm{MA}=\mathrm{CH}_{3} \mathrm{NH}_{3}{ }^{+}, \mathrm{X}=\mathrm{Cl}^{-}, \mathrm{Br}^{-}$and $\mathrm{Br} / \mathrm{I}^{-}$) can be used as semiconductor absorbers for full-colour imaging. A one-pixel photodetector prototype was constructed by stacking three layers of blue-, green- and red-sensitive $\mathrm{MAPbCl}_{3}, \mathrm{MAPbBr}_{3}$ and $\mathrm{MAPb}(\mathrm{Br} / \mathrm{I})_{3}$ crystals, respectively. The prototype detector was demonstrated to recognize and faithfully reproduce coloured images by recombination of the signals from each individual colour channel. This layered structure concept, besides imparting a two- to three-fold reduction in the number of required pixels, also offers several other advantages over conventional technologies: three times more efficient light utilization (and thus higher sensitivity) than common Bayer scheme devices based on dissipative optical filters, colour moiré suppression and no need for de-mosaic image processing. In addition, the direct band gap structure of perovskites results in optical absorption that is several orders of magnitude greater than silicon. This opens a promising avenue towards the reduction of pixel-size in next-generation devices as compared with conventional silicon-based technologies. NPG Asia Materials (2017) 9, e431; doi:10.1038/am.2017.163; published online 1 September 2017
\end{abstract}

\section{INTRODUCTION}

Out of the five main senses, sight gives the most important information about the surrounding world to Homo sapiens. ${ }^{1,2}$ It relays information as to many properties of an object such as shape, distance and size, and it also reveals colour. ${ }^{3}$ The human retina, as well as that of other coloursensing mammals, is able to differentiate between the various colours of the visible spectrum via cone cells. Cone cells exist in three different types that are each sensitive to only one colour: red, green or blue. This natural system is mimicked in three-colour arrays made from Bayer or similar dissipative filters that are selected complimentarily according to a subtractive colour model (Figure 1a). ${ }^{4}$ Although such filters are ubiquitous in technological applications, they suffer from high losses $(\sim 2 / 3$ of the total light flux) due to the absorption of light by the filters that cannot be further used. ${ }^{5,6}$ In 1999, Merrill ${ }^{6,7}$ proposed a novel solution: to stack alternatively doped silicon layers vertically rather than laterally. More recently, such configuration was applied to stacks of organic active layers integrated with MOSFET array readout integrated circuits. ${ }^{8-10}$ In this arrangement, light is consistently absorbed in each corresponding layer without excessive losses, thus maximizing the number of photons that may be used for charge carrier creation (Figure 1b). In addition to gains in optical efficiency, this design minimizes colour moiré and may, in principle, also allow higher spatial resolution. ${ }^{11,12}$ The latter possibility, however, is limited in the case of silicon due to its indirect band gap, requiring thick absorptive layers. In addition, this configuration requires a more complex and costly manufacturing process.
In this work we sought to explore a novel class of inexpensive, solution-grown semiconductor materials—organic-inorganic hybrid lead halide perovskites-as sensitive and low-cost, full-colour detector materials. For a proof-of-principle demonstration, we have used methylammonium lead halides $\left(\mathrm{MAPbX}_{3}\right.$, where $\mathrm{MA}=\mathrm{CH}_{3} \mathrm{NH}_{3}{ }^{+}$, $\mathrm{X}=\mathrm{Cl}^{-}, \mathrm{Br}^{-}, \mathrm{I}^{-}$or mixture thereof; with perovskite crystal structure, Figure 1c). The great potential of these compounds as highperformance semiconductors has been revealed over the last several years in photovoltaic research, ${ }^{13-17}$ where photovoltaic power conversion efficiencies of up to $22.1 \%$ (http://www.nrel.gov/ncpv/images/ efficiency_chart.jpg) were reported, comparable to solar cells based on traditional semiconductors such as silicon, CdTe and III-V compounds. Hybrid perovskites can be easily processed from common organic solvents into thin-film, ${ }^{18,19}$ large single crystal $(\mathrm{SC})^{20,21}$ or nanostructured forms, ${ }^{22,23}$ for use in a variety of semiconductor devices such as light-emitting diodes, ${ }^{24-26}$ lasers $^{27-30}$ and photo-, ${ }^{31-39}$ $\mathrm{X}$-ray ${ }^{40-42}$ and gamma detectors. ${ }^{21,43}$ Such a diversity of applications stems from the compelling optical and electronic characteristics of these materials: a direct band gap ${ }^{44,45}$ that is tunable in a wide range from UV to near-IR, bright and tunable emission spectra, ${ }^{8,27}$ a sharp optical absorption edge with a high extinction coefficient, ${ }^{44}$ a low density of carriers $\left(10^{9}-10^{11} \mathrm{~cm}^{-3}\right),{ }^{20,21,46,47}$ low densities of traps $\left(10^{9}-10^{10} \mathrm{~cm}^{-3}\right),{ }^{20}$ high carrier mobilities $\left(25-100 \mathrm{~cm}^{2} \mathrm{~V}^{-1} \mathrm{~s}^{-1}\right)^{21,48}$ and a long charge carrier lifetime with high exciton diffusion lengths. ${ }^{17,21}$ Important distinction between perovskites and most other

${ }^{1}$ Laboratory of Inorganic Chemistry, Department of Chemistry and Applied Biosciences, ETH Zürich, Zürich, Switzerland; ${ }^{2}$ Laboratory for Thin Films and Photovoltaics, EmpaSwiss Federal Laboratories for Materials Science and Technology, Dübendorf, Switzerland and ${ }^{3}$ Department of Photonic Processes, Institute of Physics, National Academy of Sciences of Ukraine, Kyiv, Ukraine

Correspondence: Professor MV Kovalenko, Laboratory of Inorganic Chemistry, Department of Chemistry and Applied Biosciences, ETH Zürich, Vladimir Prelog Weg 1, HCI H139, $\mathrm{CH}-8093$ Zürich, Switzerland.

E-mail: mvkovalenko@ethz.ch

Received 10 May 2017; accepted 26 June 2017 
a

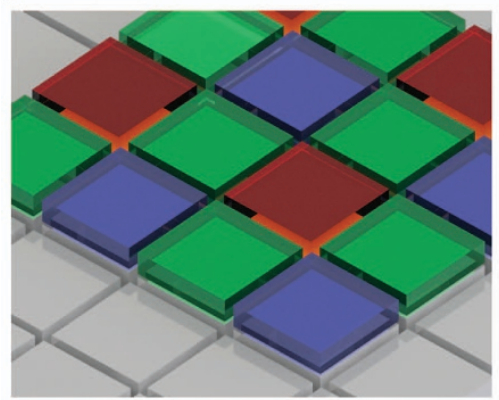

c

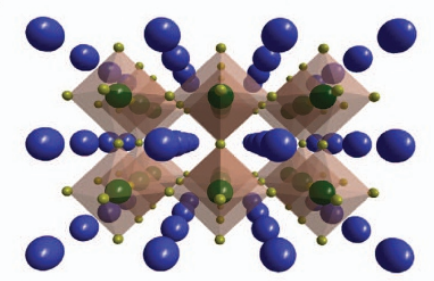

d

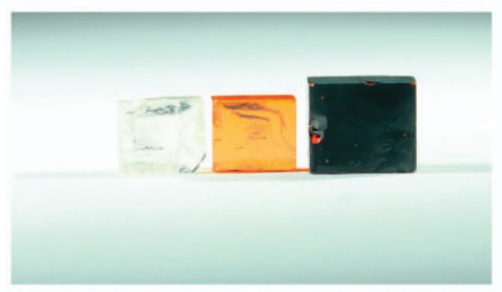

b

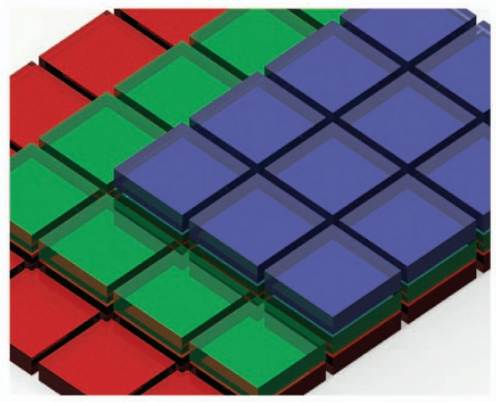

e

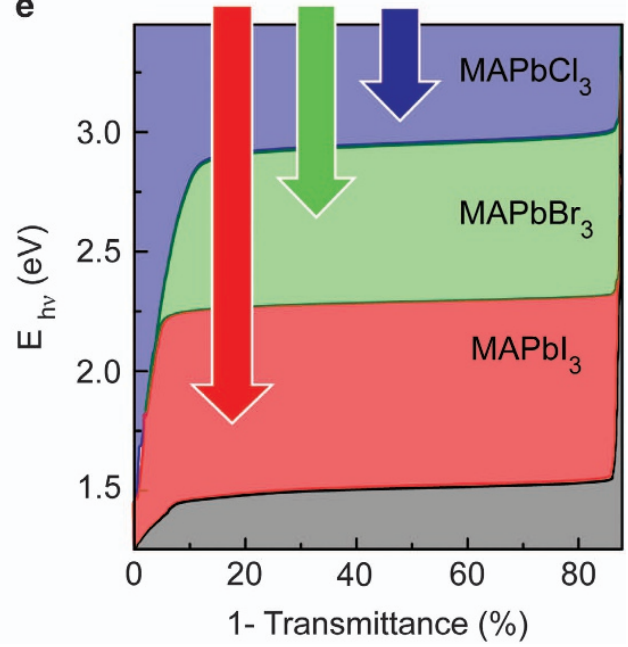

Figure 1 Realizing colour-sensitive detectors: (a) Mosaic colour sensor design, for example, consisting of Bayer filters with colour bandpass filters on top of a Si photo-sensor array; this is the conventional technology currently used in digital cameras. (b) Vertically stacked colour sensor design, where the sensors function both as active detecting layers and as long-pass filters for the underlying layers. (c) Schematic of the (idealized cubic) crystal structure of hybrid perovskites-materials with high optical absorption, efficient charge transport, and band gap tunability. Green spheres, $\mathrm{Pb}$; dark yellow spheres, halides (Cl, $\mathrm{Br}, \mathrm{I}$ ); blue spheres, methylammonium. (d) Photograph of (from left to right) typical $\mathrm{MAPbCl}_{3}, \mathrm{MAPbBr}_{3}$ and $\mathrm{MAPb}\left(\mathrm{Br} / \mathrm{I}_{3}\right.$ single crystals, which have been grown from a non-aqueous solution via the retrograde solubility method. (e) Measured light absorption of each perovskite SC used in a stack. Each layer in the detector absorbs and filters incoming light. $\mathrm{MAPbCl}_{3}$ absorbs and filters out blue wavelengths, $\mathrm{MAPbBr}_{3}$ absorbs and filters out the remaining green light and the $\mathrm{MAPb}(\mathrm{Br} /)_{3}$ absorbs the remaining light from the visible spectrum. The IR fraction of light remains unabsorbed.

semiconductors lies in their so-called defect tolerance: ${ }^{48-51}$ the structural defects that have the lowest energy of formation and thus the highest concentration do not form mid-gap states, and are therefore 'benign' towards electronic characteristics. These attributes lend promise to the possibility of replacing the thick Si absorbing layers in commercial photodetectors $(\sim 10 \mu \mathrm{m}$ or thicker $)$ with thin films of perovskites (for example, hundreds of nanometres thick).

Recently, the gradient between charge carrier collection efficiency on the surface and in the bulk of hybrid perovskites was utilized to create filter-less narrowband $(<20 \mathrm{~nm})$ detectors with high spectral selectivity. ${ }^{32,33,52}$ Herein, we report a different method that relies instead on broadband detection, again using SC detectors in the proof-of-concept demonstration. Colour selection is imparted by the vertical stacking of several SCs, each having a different band gap energy and hence acting as the optical filter for the underlying crystal(s). By stacking three $\mathrm{MAPbX}_{3}$ halides $\left(\mathrm{X}=\mathrm{Cl}^{-}\right.$for top, $\mathrm{X}=\mathrm{Br}^{-}$for middle and $\mathrm{X}=\mathrm{Br} / \mathrm{I}^{-}$for the bottom) in this manner, each crystal's resulting spectral response bandwidth closely resembles that of the cone cells in the human retina.

\section{METHODS}

Preparation of perovskite $\mathrm{MAPbX}_{3} \mathrm{SCs}$

Pristine 5-12 mm $\mathrm{MAPbX}_{3}$ SCs were prepared by procedures described elsewhere using a non-aqueous approach, ${ }^{53,54}$ with the resulting size of the SCs of $2-3 \mathrm{~mm}$ in lateral direction and about $1 \mathrm{~mm}$ in thickness. Methylammonium iodide was prepared as described elsewhere ${ }^{14}$ and washed with diethyl ether. Other methylammonium halides were prepared analogously but without washing by diethyl ether. All materials were handled in air. The SCs were rinsed with both their corresponding hydrohalic acid and 1-butanol, and stored in air. Mixed perovskite SCs were prepared by surface doping $\mathrm{MAPbBr}_{3}$ SCs using a $0.17 \mathrm{M}$ solution of methylammonium lead iodide (MAI) in t-butanol for 8-15 h at $80^{\circ} \mathrm{C}$. After anion exchange, the crystals were rinsed with 1-butanol and annealed in air at $80^{\circ} \mathrm{C}$ for $30 \mathrm{~min}$. Each SC was coated with conductive silver paste on two opposing facets for subsequent visible light response measurements. Perovskite SCs were stacked in the order: $\mathrm{MAPbCl}_{3}$ (top, facing the incident light), $\mathrm{MAPbBr}_{3}$ (middle) and $\mathrm{MAPb}(\mathrm{Br} / \mathrm{I})_{3}$ (bottom). These layers were separated by the thin insulating and transparent polymer films. One electrode of each SC was connected to bias voltage, whereas other three electrodes were connected to individual load resistors from which drop of voltage was used as a corresponding colour signals. 
Preparation of perovskite $\mathrm{MAPbX}_{3}$ films for optical absorption measurement

$\mathrm{MAPbX}_{3}$ films were deposited on glass substrates by spin-coating at 3000 r.p.m. for $60 \mathrm{~s}$ in air. The glass substrates were pre-cleaned by washing with acetone, sonication in isopropanol and water for $10 \mathrm{~min}$, and oxygen plasma treatment for $5 \mathrm{~min}$. Typically, $40 \mu \mathrm{l}$ of a $1 \mathrm{~m}$ perovskite precursor solution was dispensed onto a substrate and spin coated. The perovskite precursor solutions were the same as those used for SC growth: $1 \mathrm{~m}$ dimethyl sulfoxide:dimethylformamide (DMSO:DMF) (1:1) for $\mathrm{MAPbCl}_{3}, 1 \mathrm{~m}$ DMF for $\mathrm{MAPbBr}_{3}$ and $1 \mathrm{~m}$ gammabutyrolactone (GBL) for $\mathrm{MAPbI}_{3}$. The coated films were then placed on a hot plate set at $100^{\circ} \mathrm{C}$ for $10 \mathrm{~min}$ in air.

\section{Preparation of perovskite $\mathrm{MAPbX}_{3}$ thin film photodetectors}

Corresponding small-sized $\mathrm{MAPbX}_{3} \mathrm{SCs}$ were grinded into fine powders. The powders were mixed with calibrated silica spheres with diameter of $15 \mu \mathrm{m}$ and pressed between indium tin oxide (ITO)-coated glass substrates (active area about $0.5 \times 0.5 \mathrm{~cm}^{2}$ ). Silica spheres thus act as spacers. This configuration was mechanically fixed by epoxy glue from the edges. Saturated solutions of the corresponding perovskite precursors were filed into the remaining empty space between ITO layers in order to enable recrystallization into coarse-grained perovskite layers within the confined space. After 2 days, the solvent was dried out in a vacuum oven at $80^{\circ} \mathrm{C}$

\section{Photoconductivity and imaging}

Measurements were performed by illumination with a tungsten lamp, giving a continuous broad spectrum covering the whole visible range. The light was modulated by a mechanical chopper within a frequency range $5-1000 \mathrm{~Hz}$, whereas in photoconductivity measurements a modulation at $40 \mathrm{~Hz}$ was applied. A bias of about 3-5 V, chosen according to the stability of the dark current, was applied by a Keithley 236 SMU (Keithley Instruments, Cleveland, $\mathrm{OH}$, USA). The photoconductivity signals from each colour channel were simultaneously recorded by a Stanford Research SR-830 lock-in amplifier (Stanford Research Systems, Sunnyvale, CA, USA). The setup was controlled by a custom LabView (National Instruments Corp., Austin, TX, USA) programme. Two images were printed onto polymer transparencies using CMYK colour scheme commercial printer (HP LaserJet CM2320, Hewlett-Packard, Palo Alto, CA, USA). These transparencies were scanned in two normal to the white light beam dimensions by $50 \mathrm{~mm}$ translation stages (Thorlabs MTS50/M-Z8E, Thorlabs, Inc. Newton, NJ, USA). For photoconductivity spectrum measurements, the white light from the tungsten lamp was monochromatized by an Acton SP2150 (Princeton Instruments, Trenton, NJ, USA) spectrograph/ monochromator and $50 \%$ of the monochromatized light was redirected by a polka-dot beamsplitter (Thorlabs BPD508-FS, Thorlabs, Inc., Newton, NJ, USA) to the reference channel that consisted of a power calibrated pyroelectric detector (UM9B-BL, Gentec-EO, Québec City, Quebec, Canada).

\section{Optical absorption characterization}

UV-visible absorption spectra of the perovskite films were collected using a Jasco V670 (Jasco Labor- u. Datentechnik GmbH, Gross-Umstadt, Germany) spectrometer equipped with an integrating sphere, whereas SCs were measured in transmission mode on custom-made apertures. Absorption coefficients were re-calculated according to the film thickness determined as the average of five measurements on a stylus profilometer

\section{RESULTS}

\section{Device fabrication}

One of the major advantages of $\mathrm{MAPbX}_{3}$ semiconductors is facile compositional tuning of their band gap energies over the whole visible spectral range by adjusting the halide composition. ${ }^{27}$ For this proof-ofthe concept study, we have used SCs of such compounds (Figure 1d) due to their superior electronic characteristics as compared with polycrystalline thin films and simplicity of the device fabrication. Rectangular-prism-shaped $\mathrm{MAPbCl}_{3}$ and $\mathrm{MAPbBr}_{3}$ SCs were grown from $1 \mathrm{M}$ dimethyl sulfoxide:DMF $(1: 1)$ and DMF solutions at temperatures of $50^{\circ} \mathrm{C}$ and $80^{\circ} \mathrm{C}$, respectively, following the synthesis methodology previously described. ${ }^{53,54} \mathrm{MAPb}(\mathrm{Br} / \mathrm{I})_{3} \quad \mathrm{SCs}$ were obtained by dipping $\mathrm{MAPbBr}_{3} \mathrm{SCs}$ into a solution of MAI in t-butanol at $80^{\circ} \mathrm{C}$ for $8-15 \mathrm{~h}$, leading to Br-to-I anion exchange in the surface region. We assume that the detection of light by such SCs occurs primarily within this I-rich region. The choice $\mathrm{MAPb}(\mathrm{Br} / \mathrm{I})_{3} \mathrm{SCs}$ as the bottom layer in our prototype is based on its higher electronic stability (presumably owing to reduced ionic drift ${ }^{43,55}$ ) and flat, prismatic shape (convenient for stacking), as compared with $\mathrm{MAPbI}_{3} \cdot \mathrm{MAPbI}_{3}$ SCs happen to have a bulkier, faceted appearance.

The band gaps of the $\mathrm{MAPbX}_{3}$ SCs are such that the chloride absorbs only the blue wavelengths from the visible spectrum, the bromide absorbs blue and green, and the iodide remains opaque; that is, each layer also has the role of a long-pass optical filter for the underlying layer, as illustrated by the absorption spectra in Figure 1e. Contrary to band-pass filters in a Bayer scheme (Figure 1a), in a vertical stacking scheme (Figure $1 \mathrm{~b}$ ) the light is not dissipated in the long-pass filters serving as upper layers, but is instead converted into photogenerated charge carriers. In this way, two-thirds of the light that is normally lost by spectral rejection in a Bayer subtractive filter system can be efficiently utilized.

\section{Multicolour detection}

In order to proof the applicability of lead halide perovskites as active materials in 'Foveon-like' photodetector with complimentary absorption properties, we constructed a simple assembly from three vertically stacked perovskite SCs: $\mathrm{MAPbCl}_{3}$ as the top layer, $\mathrm{MAPbBr}_{3}$ as the middle layer and $\mathrm{MAPb}(\mathrm{Br} / \mathrm{I})_{3}$ as the bottom layer,electrically isolated one from another by polymer films (Figure 2a). We used a configuration with three parallel registration channels (Figures 2a and b) with four electrical terminals (where one terminal is common to all three SCs). Photoconductivity measurements of the individual SCs illustrate the active optical filtering of blue, green and red wavelengths by $\mathrm{MAPbCl}_{3}, \mathrm{MAPbBr}_{3}$ and $\mathrm{MAPb}(\mathrm{Br} / \mathrm{I})_{3} \mathrm{SCs}$, respectively (Figure 2c). Detailed optoelectronic characterization of the individual photodetectors is presented in Supplementary Figures 1 and 2. The sharp cut-off wavelengths of detection on the longer- and shorter-wavelength sides within each layer, respectively, are determined by the sharp absorption edge of the SC in that layer (on the long-wavelength cut-off) and by that of the layer above (on the short-wavelength side, as in the cases of the $\mathrm{Br}$ and $\mathrm{Br} / \mathrm{I} \mathrm{SCs}$ ). Without this specific stacking order, the photoresponsivities of $\mathrm{MAPbBr}_{3}$ and $\mathrm{MAPb}(\mathrm{Br} / \mathrm{I})_{3}$ would both extend from their band-edge to ultraviolet wavelengths (Supplementary Figure 1). Perovskite SCs demonstrate linearity of the photoresponse within biasing range of $0-10 \mathrm{~V}$ (Supplementary Figure 2a). $\mathrm{MAPbCl}_{3}$ and $\mathrm{MAPbBr}_{3}$ SCs exhibit linear behaviour vs incident light intensity, whereas response of $\mathrm{MAPb}(\mathrm{Br} / \mathrm{I})_{3}$ saturates, presumably due to traps or ionic drift. All perovskite SCs have low dark current and relatively fast photoresponse with bandwidth of at least $50 \mathrm{~Hz}$ (Supplementary Figures $2 b$ and $d)$.

To test the prototype detector, we first printed several images of various complexities onto polymer transparencies (using a laser printer, with a CMYK colour pallet). We then recorded these images on transparencies using perovskite detector. For this, transparencies were placed between the detector and white-light illumination (by incandescent halogen lamp). The white light was focused to a $1 \mathrm{~mm}$ beam, thus defining the final resolution of the image. This beam propagated through the transparency and was detected by the detector. To reproduce the images using a perovskite detector, the transparency was two-dimensionally scanned around this beam. The test images consisted of an image of simple stripes of seven colours (each stripe 

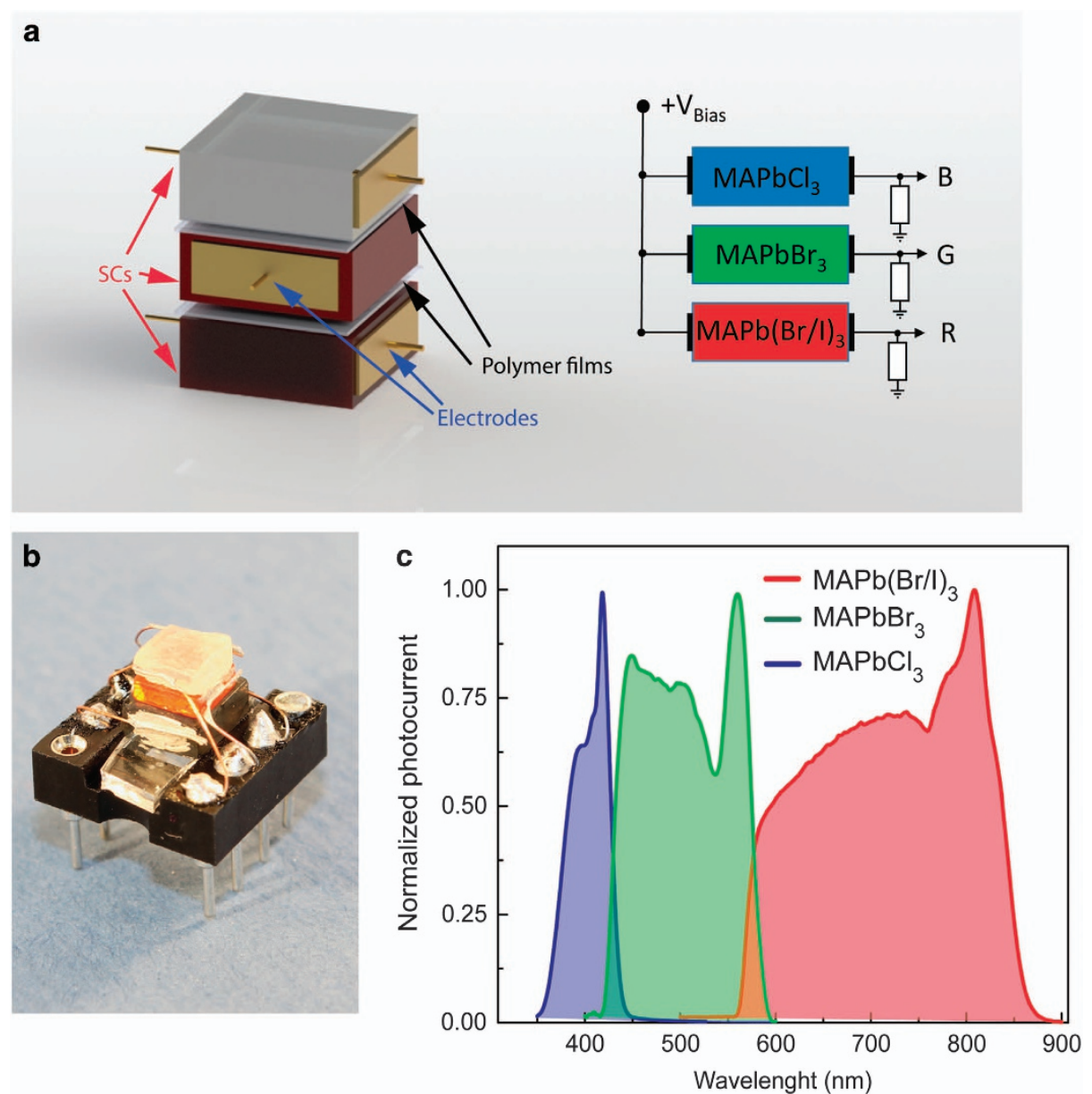

Figure 2 Photoconductivity of a full-colour perovskite detector. (a) Sketch of stacked SC photodetector and its electrical connection scheme. (b) Photograph of the prototype detector assembled from three SCs stacked on a chip carrier: $\mathrm{MAPbCl}_{3}$ on the top, $\mathrm{MAPbBr}_{3}$ in the middle and $\mathrm{MAPb}\left(\mathrm{Br} / \mathrm{I}_{3}\right.$ on the bottom. (c) Normalized photoconductivity spectra of the individual SCs in the stacked detector presented in $\mathbf{b}$. The spectra do not significantly overlap, indicating a long-pass filtering effect from one layer to the next.

$7 \mathrm{~mm}$ in width, Figures 3a-e) and a photograph of bright photoluminescence from colloidal $\mathrm{CsPbX}$ nanocrystals in flasks $\left(\mathrm{X}=\mathrm{Cl}^{-}\right.$, $\mathrm{Br}^{-}, \mathrm{I}^{-}$and $\mathrm{Cl} / \mathrm{Br}^{-}$or $\mathrm{Br} / \mathrm{I}^{-}$systems, Figures $3 \mathrm{f}-\mathrm{j}$ ). These perovskite NCs have been recently demonstrated to produce bright, pure colours that span the entire visible range with a large colour gamut $(146 \%$ of the National Television System Committee standard). ${ }^{56}$

The results of scanning the image of colour stripes with the prototype detector are presented as a series of photoconductivity charts: one from each of the three channels (red, green and blue, recorded simultaneously, Figures $3 \mathrm{~b}-\mathrm{d}$ ). These three graphs reproduce the transmitted portion of the light in the red, green and blue spectral regions. By comparing the signal intensity in each channel, it is possible to determine the original, incident colour of light. For example, a blue-coloured stripe yields the highest signal as recorded by the $\mathrm{MAPbCl}_{3}$ channel, whereas red- and green-coloured stripes yield the highest signals from the $\mathrm{MAPb}(\mathrm{Br} / \mathrm{I})_{3}$ and $\mathrm{MAPbBr}_{3}$ channels, respectively. In addition, the white regions between the stripes produce maxima in each channel, whereas the black stripe produces a minimum in each. The yellow colour, in the subtractive colour model, is complimentary to blue; the yellow stripe is therefore identified by a high signal in both the $\mathrm{MAPbBr}_{3}$ (green) and $\mathrm{MAPb}$ $(\mathrm{Br} / \mathrm{I})_{3}$ (red) channels, but a low signal in the $\mathrm{MAPbCl}_{3}$ (blue) channel. By combining the information obtained from these three channels, and using the black and white areas for normalization and colour balance, it is possible (rather easily) to reproduce the initial image of the stripes (Figure 3e).

The prototype red-green-blue (RGB) detector was also able to faithfully reproduce the second test image (Figure $3 \mathrm{f}$ ) with impressive colour transmission quality by combining the signals from the individual channels (Figure 3j). The green and red flasks within the image produced the highest signals within the corresponding $\mathrm{MAPbBr}_{3}$ and $\mathrm{MAPb}(\mathrm{Br} / \mathrm{I})_{3}$ channels (Figures $3 \mathrm{~g}$ and $\mathrm{h}$ ). Similarly, the blue flask appeared brightest in the $\mathrm{MAPbCl}_{3}$ channel (Figure 3i). The image was reproduced, containing some minor artefacts as a result of the limited resolution of the scanning method.

\section{DISCUSSION}

To the best of our knowledge, the only commercialized colour sensor using a vertical layer arrangement, namely silicon layers of various doping compositions, is referred to by the tradename Foveon X3 (Sigma Corp., Kawasaki, Kanagawa, Japan), used in professional digital single-lens reflex cameras produced by Sigma Corporation. In that case, the optical filtering effect is achieved in one continuous silicon slab. In a vertical direction, each silicon slab contains three epitaxially grown active regions of different thickness; as a result of the steep absorption vs wavelength dependence of silicon (Figure 4a), these layers act as filters and detectors at the same time. For discriminative and efficient collection of photogenerated carriers, the 
a

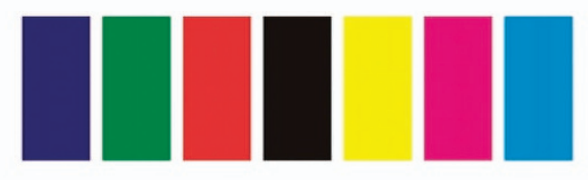

b

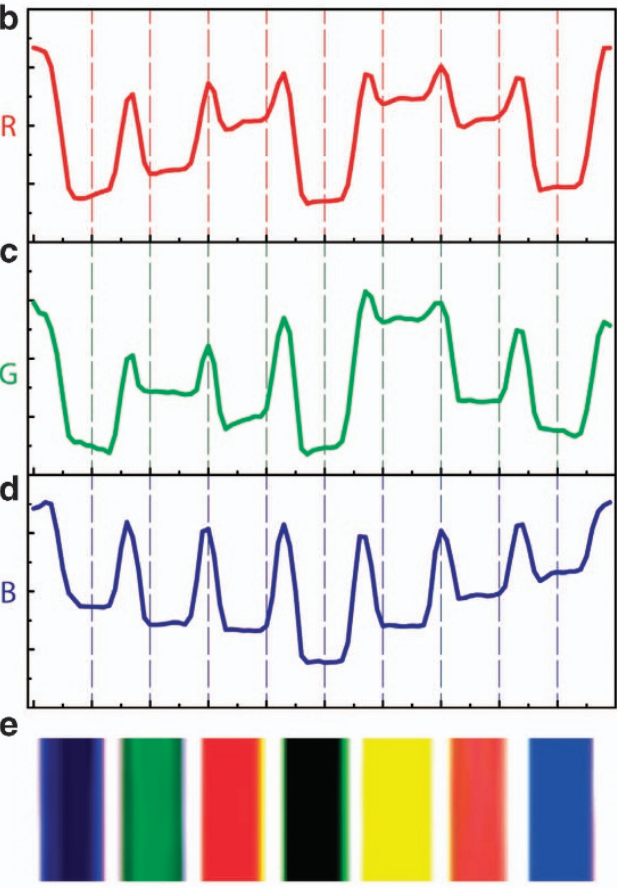

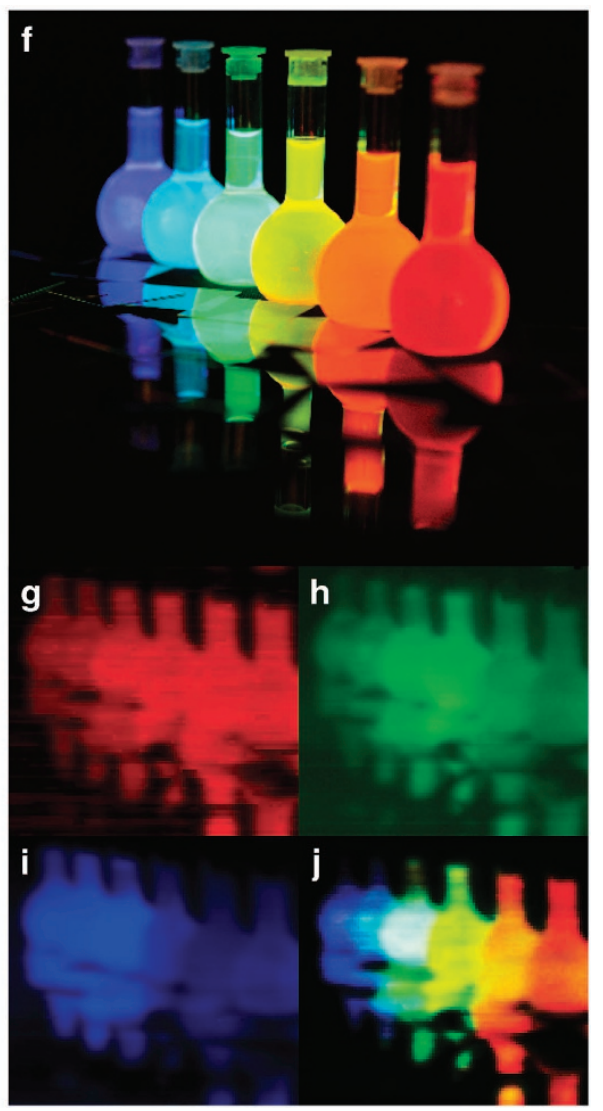

Figure 3 Demonstration of colour sensing for stacked perovskite SC detector. (a) Test transparency consisting of seven coloured stripes. (b-d) Photocurrent signals measured from a spatial scan of the detector across the series of coloured stripes in a. Red (R), green (G) and blue (B) channels correspond to MAPb $(\mathrm{Br} / \mathrm{l})_{3}, \mathrm{MAPbBr}_{3}$ and $\mathrm{MAPbCl}_{3} \mathrm{SCs}$, respectively. (e) Reproduction of the test transparency in a by merging the R, G and $\mathrm{B}$ channels in (b-d). (f) Test transparency showing a series of flasks containing fluorescing colloidal solutions of perovskite nanocrystals. The size of the image is $5 \times 5 \mathrm{~cm}$. Reprinted in part with permission from Nano Letters, June 10, 2015, 15(6), cover. Copyright 2015 American Chemical Society. (g-i) Corresponding R, G and B channels obtained by two-dimensionally scanning the detector across the test image in $\mathbf{f}$. (j) Reproduction of the test transparency in $\mathbf{f}$ by merging the $R$, $G$ and $B$ channels in $\mathbf{g}-\mathbf{i}$.

a

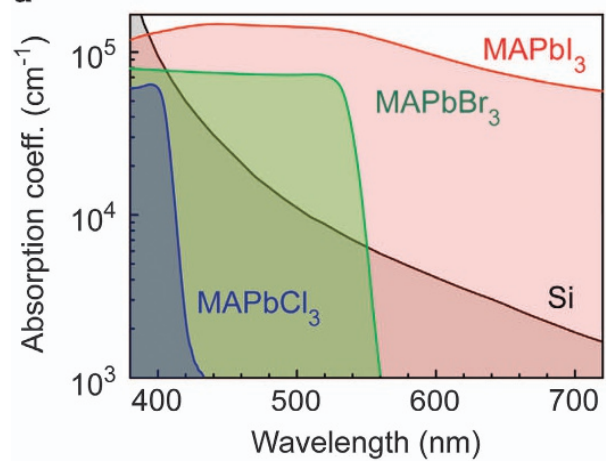

b

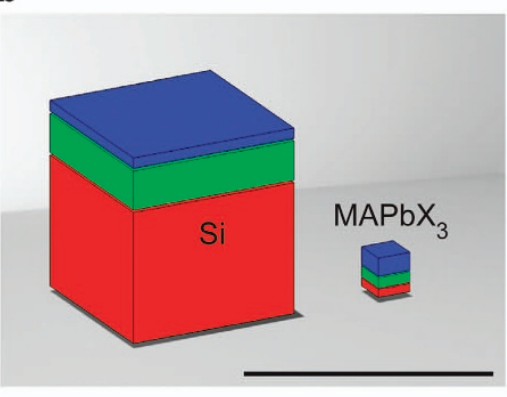

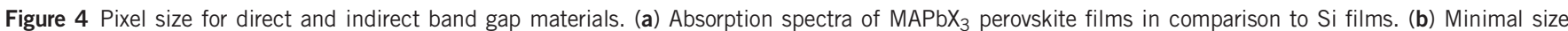
of pixels composed of stacked layers of Si compared with $\mathrm{MAPbX}_{3}$ perovskites. The minimal thickness of each layer is determined by the penetration depth of light. This affects the minimal lateral pixel size, which scales with pixel thickness. The scale bar is $10 \mu \mathrm{m}$.

layers are doped alternatively as $\mathrm{n}$ - or p-type, as described in detail elsewhere. ${ }^{6}$ Clearly, the majority of the crystal is then used for detecting red light. While having many advantages such as the absence of moiré and de-mosaicing artefacts, this technology is costly due to its elaborate fabrication method. Furthermore, due to the sloping absorption spectrum of silicon, a fraction of green and red light is still absorbed in the upper layers, causing substantial sensitivity losses and colour blurring.

Conceptually, hybrid perovskite photodetectors are a highly promising alternative to silicon-based vertically stacked detectors, due to their inexpensive and robust growth in the form of thin films or SCs and due to their high absorption coefficients and tunable band gaps. 
The magnitude of the light absorption coefficient directly translates into the thickness required for efficient photon absorption when acting as a filter as well as for photodetection. For example, the absorption coefficient of $\mathrm{MAPbBr}_{3}$ in the green region is one order of magnitude higher than that of silicon (Figure 4a); this difference reaches two orders of magnitude for $\mathrm{MAPbI}_{3}$ in the red end of the visible range. Only on the blue side, below $420 \mathrm{~nm}$, do $\mathrm{MAPbCl}_{3}$ and silicon exhibit similar absorption coefficients. Figure $4 \mathrm{~b}$ presents this comparison between silicon and perovskites in terms of the required thickness of each layer and, correspondingly, the lateral size of the pixel. A much higher spatial resolution, down to $1 \mu \mathrm{m}$, can be anticipated ${ }^{57}$ for perovskite based detectors, almost approaching the Abbe diffraction limit for visible light $(1 \mu \mathrm{m}$ is roughly $1.5-2.5$ wavelengths). Although it is not needed for most commercial applications such as digital cameras, a much higher spatial resolution is desired for emerging technologies such as Stationary-Wave Integrated Fourier Transform Spectrometry. ${ }^{58}$ An additional advantage of perovskites over silicon is the possibility for facile tuning of the band gap by anion exchange, resulting in mixed halide compositions which allow the precise adjustment of the cut-off at the short-wavelength edge of the visible range. This, contrary to the case for silicon, may well eliminate the need for IR-rejecting layers.

To probe the feasibility of the eventual development of an array detector with stacked perovskite layers we have tested thinner, $15 \mu \mathrm{m}$ layers. Such layers were grown in-between ITO electrodes (see Methods for experimental details) and exhibited photoconductivity spectra that are flat and blue-shifted with regard to bulk SCs (see Supplementary Figure 1). Thin perovskite photodetectors demonstrate nonlinear bias characteristics (presumably due to Schottky-like barriers at the ITO) with narrower operational range of biases (Supplementary Figure 3a). Above $2 \mathrm{~V}$, photoresponsivity declined. These layers are characterized by notably higher dark currents (owing to thin active layers) and lower linearity of the photoresponse vs light intensity dependence. At the same time, such thin perovskite photodetectors still demonstrated fast photoresponse (Supplementary Figure 3d). Thin perovskite films are promising for application as active layers on top of metal-oxide field effect transistors to form hybrid phototransistors ${ }^{9,10}$ that are compatible for further addressing by read-out integrated circuits in an array. Recently, perovskites have been successfully implemented as absorbing layers in hybrid phototransistors. ${ }^{59}$ Direct contact of perovskite layers appears challenging in the view of known halide-ion mixing. This problem might be mitigated by insertion electrically conductive, optical transparent and halide-ion-impermeable contact layers.

In conclusion, a perovskite-based, one-pixel RGB colour sensor with a vertical layer stacking design was demonstrated. It was shown that this prototype detector could faithfully reproduce simple onedimensional images and realistic two-dimensional images with excellent colour resolution. Such vertically layered detectors may offer several advantages over traditional Bayer-type dissipative and subtractive optically filtered detectors: a potentially higher spatial resolution, improved optical efficiency and suppressed incidence of colour moiré and de-mosaicing artefacts. ${ }^{60}$ Future work to fabricate thin-film stacks of perovskite layers in the same manner should be carried out and recent reports indicate the possibility of the substrate-supported growth of flat, micrometre-thick perovskite SCs. ${ }^{35,36}$

\section{CONFLICT OF INTEREST}

The authors declare no conflict of interest.

\section{ACKNOWLEDGEMENTS}

MK acknowledges financial support from the European Union through the FP7 (ERC Starting Grant NANOSOLID, GA number 306733). We thank Sudhir Kumar for the profilometry measurements, Georgian Nedelcu for a 3D-sketch of perovskite structure, and Nicholas Stadie and Bogdan Benin for reading the manuscript.

Author contributions: SY and MK conceived and planned the work. SY and YS performed measurements of the photo response of perovskite SCs. SY analysed the results. DD and IC grew perovskite SCs. MK supervised the work. SY and MK wrote the manuscript. All authors discussed the results and commented on the manuscript.

\section{PUBLISHER'S NOTE}

Springer Nature remains neutral with regard to jurisdictional claims in published maps and institutional affiliations.

1 Kreiman, G., Koch, C. \& Fried, I. Imagery neurons in the human brain. Nature 408, 357-361 (2000).

2 Wassle, H. Parallel processing in the mammalian retina. Nat. Rev. Neurosci. 5, 747-757 (2004)

3 Livingstone, M. \& Hubel, D. Segregation of form, color, movement, and depth: anatomy, physiology, and perception. Science 240, 740-749 (1988).

4 Jansen-van Vuuren, R. D., Armin, A., Pandey, A. K., Burn, P. L. \& Meredith, P. Organic photodiodes: the future of full color detection and image sensing. Adv. Mater. 28, 4766-4802 (2016).

5 Nishiwaki, S., Nakamura, T., Hiramoto, M., Fujii, T. \& Suzuki, M.-a. Efficient colour splitters for high-pixel-density image sensors. Nat. Photonics 7, 248-254 (2013).

6 Merrill, R. B. Color separation in an active pixel cell imaging array using a triple-well structure. Patent US5965875 (1999).

7 Merrill, R. B. Vertical color filter detector group and array. Patent US6727521 (2003).

8 Lim, S.-J., Leem, D.-S., Park, K.-B., Kim, K.-S., Sul, S., Na, K., Lee, G. H., Heo, C.-J., Lee, K.-H., Bulliard, X., Satoh, R.-I., Yagi, T., Ro, T., Im, D., Jung, J., Lee, M., Lee, T.-Y., Han, M. G., Jin, Y. W. \& Lee, S. Organic-on-silicon complementary metaloxide-semiconductor colour image sensors. Sci. Rep. 5, 7708 (2015).

9 Aihara, S., Seo, H., Namba, M., Watabe, T., Ohtake, H., Kubota, M., Egami, N., Hiramatsu, T., Matsuda, T., Furuta, M., Nitta, H. \& Hirao, T. Stacked image sensor with green- and red-sensitive organic photoconductive films applying zinc oxide thin-film transistors to a signal readout circuit. IEEE Trans. Electron Dev. 56, 2570-2576 (2009).

10 Hokuto, S., Satoshi, A., Toshihisa, W., Hiroshi, O., Toshikatsu, S., Misao, K., Norifumi, E., Takahiro, H., Tokiyoshi, M., Mamoru, F. \& Takashi, H. A 128×96 pixel stack-type color image sensor: stack of individual blue-, green-, and red-sensitive organic photoconductive films integrated with a $\mathrm{ZnO}$ thin film transistor readout circuit. Jpn. J. Appl. Phys. 50, 024103-024106 (2011).

11 Rueda, H., Lau, D. \& Arce, G. R. Multi-spectral compressive snapshot imaging using RGB image sensors. Opt. Express 23, 12207-12221 (2015).

12 Equis, S., Schnabel, R. \& Jacquot, P. Snap-shot profilometry with the empirical mode decomposition and a 3-layer color sensor. Opt. Express 19, 1284-1290 (2011).

13 Burschka, J., Pellet, N., Moon, S.-J., Humphry-Baker, R., Gao, P., Nazeeruddin, M. K. \& Gratzel, M. Sequential deposition as a route to high-performance perovskitesensitized solar cells. Nature 499, 316-319 (2013).

14 Lee, M. M., Teuscher, J., Miyasaka, T., Murakami, T. N. \& Snaith, H. J. Efficient hybrid solar cells based on meso-superstructured organometal halide perovskites. Science 338, 643-647 (2012).

15 Liu, M., Johnston, M. B. \& Snaith, H. J. Efficient planar heterojunction perovskite solar cells by vapour deposition. Nature 501, 395-398 (2013).

16 Stranks, S. D., Eperon, G. E., Grancini, G., Menelaou, C., Alcocer, M. J. P., Leijtens, T., Herz, L. M., Petrozza, A. \& Snaith, H. J. Electron-hole diffusion lengths exceeding 1 micrometer in an organometal trihalide perovskite absorber. Science 342, 341-344 (2013).

17 Xing, G., Mathews, N., Sun, S., Lim, S. S., Lam, Y. M., Grätzel, M., Mhaisalkar, S. \& Sum, T. C. Long-range balanced electron- and hole-transport lengths in organicinorganic $\mathrm{CH}_{3} \mathrm{NH}_{3} \mathrm{Pbl}_{3}$. Science 342, 344-347 (2013).

18 Zhang, W., Saliba, M., Moore, D. T., Pathak, S. K., Hörantner, M. T., Stergiopoulos, T., Stranks, S. D., Eperon, G. E., Alexander-Webber, J. A., Abate, A., Sadhanala, A., Yao, S., Chen, Y., Friend, R. H., Estroff, L. A., Wiesner, U. \& Snaith, H. J. Ultrasmooth organic-inorganic perovskite thin-film formation and crystallization for efficient planar heterojunction solar cells. Nat. Commun. 6, 7142 (2015).

19 Yang, S., Wang, Y., Liu, P., Cheng, Y.-B., Zhao, H. J. \& Yang, H. G. Functionalization of perovskite thin films with moisture-tolerant molecules. Nat. Energy 1, 15016 (2016).

20 Shi, D., Adinolfi, V., Comin, R., Yuan, M., Alarousu, E., Buin, A., Chen, Y., Hoogland, S., Rothenberger, A., Katsiev, K., Losovyj, Y., Zhang, X., Dowben, P. A., Mohammed, O. F., Sargent, E. H. \& Bakr, O. M. Low trap-state density and long carrier 
diffusion in organolead trihalide perovskite single crystals. Science 347, 519-522 (2015).

21 Dong, Q., Fang, Y., Shao, Y., Mulligan, P., Qiu, J., Cao, L. \& Huang, J. Electron-hole diffusion lengths $>175 \mu \mathrm{m}$ in solution-grown $\mathrm{CH}_{3} \mathrm{NH}_{3} \mathrm{Pbl}_{3}$ single crystals. Science 347, 967-970 (2015).

22 Zhang, F., Zhong, H., Chen, C., Wu, X.-g., Hu, X., Huang, H., Han, J., Zou, B. \& Dong, Y. Brightly luminescent and color-tunable colloidal $\mathrm{CH}_{3} \mathrm{NH}_{3} \mathrm{PbX}_{3}(\mathrm{X}=\mathrm{Br}, \mathrm{I}, \mathrm{Cl})$ quantum dots: potential alternatives for display technology. ACS Nano 9, 4533-4542 (2015).

23 Vybornyi, O., Yakunin, S. \& Kovalenko, M. V. Polar-solvent-free colloidal synthesis of highly luminescent alkylammonium lead halide perovskite nanocrystals. Nanoscale $\mathbf{8}$, 6278-6283 (2016).

24 Cho, H., Jeong, S.-H., Park, M.-H., Kim, Y.-H., Wolf, C., Lee, C.-L., Heo, J. H., Sadhanala, A., Myoung, N., Yoo, S., Im, S. H., Friend, R. H. \& Lee, T.-W. Overcoming the electroluminescence efficiency limitations of perovskite light-emitting diodes. Science 350, 1222-1225 (2015)

25 Tan, Z.-K., Moghaddam, R. S., Lai, M. L., Docampo, P., Higler, R., Deschler, F., Price, M., Sadhanala, A., Pazos, L. M., Credgington, D., Hanusch, F., Bein, T., Snaith, H. J. \& Friend, R. H. Bright light-emitting diodes based on organometal halide perovskite. Nat. Nanotechnol. 9, 687-692 (2014).

26 Pan, J., Quan, L. N., Zhao, Y., Peng, W., Murali, B., Sarmah, S. P., Yuan, M., Sinatra, L., Alyami, N. M., Liu, J., Yassitepe, E., Yang, Z., Voznyy, O., Comin, R., Hedhili, M. N., Mohammed, O. F., Lu, Z. H., Kim, D. H., Sargent, E. H. \& Bakr, O. M. Highly efficient perovskite-quantum-dot light-emitting diodes by surface engineering. Adv. Mater. 28, 8718-8725 (2016).

27 Xing, G., Mathews, N., Lim, S. S., Yantara, N., Liu, X., Sabba, D., Grätzel, M., Mhaisalkar, S. \& Sum, T. C. Low-temperature solution-processed wavelength-tunable perovskites for lasing. Nat. Mater. 13, 476-480 (2014).

28 Yakunin, S., Protesescu, L., Krieg, F., Bodnarchuk, M. I., Nedelcu, G., Humer, M. De Luca, G., Fiebig, M., Heiss, W. \& Kovalenko, M. V. Low-threshold amplified spontaneous emission and lasing from colloidal nanocrystals of caesium lead halide perovskites. Nat. Commun. 6, 9056 (2015).

29 Zhu, H., Fu, Y., Meng, F., Wu, X., Gong, Z., Ding, Q., Gustafsson, M. V., Trinh, M. T. Jin, S. \& Zhu, X. Y. Lead halide perovskite nanowire lasers with low lasing thresholds and high quality factors. Nat. Mater. 14, 636-642 (2015).

30 Pan, J., Sarmah, S. P., Murali, B., Dursun, I., Peng, W., Parida, M. R., Liu, J., Sinatra, L., Alyami, N., Zhao, C., Alarousu, E., Ng, T. K., Ooi, B. S., Bakr, O. M. \& Mohammed, O. F. Air-stable surface-passivated perovskite quantum dots for ultrarobust, single- and two-photon-induced amplified spontaneous emission. J. Phys. Chem. Lett. 6, 5027-5033 (2015).

31 Dou, L., Yang, Y., You, J., Hong, Z., Chang, W.-H., Li, G. \& Yang, Y. Solution-processed hybrid perovskite photodetectors with high detectivity. Nat. Commun. 5, 6404 (2014).

32 Fang, Y., Dong, Q., Shao, Y., Yuan, Y. \& Huang, J. Highly narrowband perovskite singlecrystal photodetectors enabled by surface-charge recombination. Nat. Photonics 9 679-686 (2015)

33 Lin, Q., Armin, A., Burn, P. L. \& Meredith, P. Filterless narrowband visible photodetectors. Nat. Photonics 9, 687-694 (2015).

34 Sutherland, B. R., Johnston, A. K., Ip, A. H., Xu, J., Adinolfi, V., Kanjanaboos, P. \& Sargent, E. H. Sensitive, fast, and stable perovskite photodetectors exploiting interface engineering. ACS Photonics 2, 1117-1123 (2015).

35 Saidaminov, M. I., Adinolfi, V., Comin, R., Abdelhady, A. L., Peng, W., Dursun, I., Yuan, M., Hoogland, S., Sargent, E. H. \& Bakr, O. M. Planar-integrated singlecrystalline perovskite photodetectors. Nat. Commun. 6, 9724 (2015).

36 Saidaminov, M. I., Haque, M. A., Savoie, M., Abdelhady, A. L., Cho, N., Dursun, I., Buttner, U., Alarousu, E., Wu, T. \& Bakr, O. M. Perovskite photodetectors operating in both narrowband and broadband regimes. Adv. Mater. 28, 8144-8149 (2016).

37 Murali, B., Saidaminov, M. I., Abdelhady, A. L., Peng, W., Liu, J., Pan, J., Bakr, O. M. \& Mohammed, O. F. Robust and air-stable sandwiched organo-lead halide perovskites for photodetector applications. J. Mater. Chem. C 4, 2545-2552 (2016).

38 Chen, S., Teng, C., Zhang, M., Li, Y., Xie, D. \& Shi, G. A flexible UV-Vis-NIR photodetector based on a perovskite/conjugated-polymer composite. Adv. Mater. 28 5969-5974 (2016).

39 Wang, W., Xu, H., Cai, J., Zhu, J., Ni, C., Hong, F., Fang, Z., Xu, F., Cui, S., Xu, R., Wang, L., Xu, F. \& Huang, J. Visible blind ultraviolet photodetector based on $\mathrm{CH}_{3} \mathrm{NH}_{3} \mathrm{PbCl}_{3}$ thin film. Opt. Express 24, 8411-8419 (2016).

40 Yakunin, S., Sytnyk, M., Kriegner, D., Shrestha, S., Richter, M., Matt, G. J., Azimi, H., Brabec, C. J., Stangl, J., Kovalenko, M. V. \& Heiss, W. Detection of X-ray photons by solution-processed lead halide perovskites. Nat. Photonics 9, 444-449 (2015).

41 Wei, H., Fang, Y., Mulligan, P., Chuirazzi, W., Fang, H.-H., Wang, C., Ecker, B. R., Gao, Y., Loi, M. A., Cao, L. \& Huang, J. Sensitive X-ray detectors made of methylammonium lead tribromide perovskite single crystals. Nat. Photonics 10, 333-339 (2016).

42 Náfrádi, B., Náfrádi, G., Forró, L. \& Horváth, E. Methylammonium lead iodide for efficient X-ray energy conversion. J. Phys. Chem. C 119, 25204-25208 (2015).
43 Yakunin, S., Dirin, D. N., Shynkarenko, Y., Morad, V., Cherniukh, I., Nazarenko, O., Kreil, D., Nauser, T. \& Kovalenko, M. V. Detection of gamma photons using solution-grown single crystals of hybrid lead halide perovskites. Nat. Photonics 10, 585-589 (2016).

44 De Wolf, S., Holovsky, J., Moon, S.-J., Löper, P., Niesen, B., Ledinsky, M., Haug, F.-J., Yum, J.-H. \& Ballif, C. Organometallic halide perovskites: sharp optical absorption edge and its relation to photovoltaic performance. J. Phys. Chem. Lett. 5, 1035-1039 (2014).

45 Motta, C., El-Mellouhi, F., Kais, S., Tabet, N., Alharbi, F. \& Sanvito, S. Revealing the role of organic cations in hybrid halide perovskite $\mathrm{CH}_{3} \mathrm{NH}_{3} \mathrm{Pbl}_{3}$. Nat. Commun. 6 , 8026 (2015).

46 Zhumekenov, A. A., Saidaminov, M. I., Haque, M. A., Alarousu, E., Sarmah, S. P., Murali, B., Dursun, I., Miao, X.-H., Abdelhady, A. L., Wu, T., Mohammed, O. F. \& Bakr, O. M. Formamidinium lead halide perovskite crystals with unprecedented long carrier dynamics and diffusion length. ACS Energy Lett. 1, 32-37 (2016).

47 Hao, F., Stoumpos, C. C., Chang, R. P. H. \& Kanatzidis, M. G. Anomalous band gap behavior in mixed sn and pb perovskites enables broadening of absorption spectrum in solar cells. J. Am. Chem. Soc. 136, 8094-8099 (2014).

48 Manser, J. S., Christians, J. A. \& Kamat, P. V. Intriguing optoelectronic properties of metal halide perovskites. Chem. Rev. 116, 12956-13008 (2016).

49 Zakutayev, A., Caskey, C. M., Fioretti, A. N., Ginley, D. S., Vidal, J., Stevanovic, V., Tea, E. \& Lany, S. Defect tolerant semiconductors for solar energy conversion. J. Phys. Chem. Lett. 5, 1117-1125 (2014).

50 Brandt, R. E., Stevanović, V., Ginley, D. S. \& Buonassisi, T. Identifying defect-tolerant semiconductors with high minority-carrier lifetimes: beyond hybrid lead halide perovskites. MRS Commun. 5, 265-275 (2015).

51 Buin, A., Pietsch, P., Xu, J., Voznyy, O., Ip, A. H., Comin, R. \& Sargent, E. H. Materials processing routes to trap-free halide perovskites. Nano Lett. 14, 6281-6286 (2014).

52 Armin, A., Jansen-van Vuuren, R. D., Kopidakis, N., Burn, P. L. \& Meredith, P. Narrowband light detection via internal quantum efficiency manipulation of organic photodiodes. Nat. Commun. 6, 6343 (2015).

53 Maculan, G., Sheikh, A. D., Abdelhady, A. L., Saidaminov, M. I., Haque, M. A., Murali, B., Alarousu, E. E., Mohammed, O. F., Wu, T. \& Bakr, O. M. $\mathrm{CH}_{3} \mathrm{NH}_{3} \mathrm{PbCl}_{3}$ single crystals: inverse temperature crystallization and visible-blind UV-photodetector. J. Phys. Chem. Lett. 6, 3781-3786 (2015).

54 Saidaminov, M. I., Abdelhady, A. L., Murali, B., Alarousu, E., Burlakov, V. M., Peng, W., Dursun, I., Wang, L., He, Y., Maculan, G., Goriely, A., Wu, T., Mohammed, O. F. \& Bakr, O. M. High-quality bulk hybrid perovskite single crystals within minutes by inverse temperature crystallization. Nat. Commun. 6, 8586 (2015).

55 Eames, C., Frost, J. M., Barnes, P. R. F., O/'Regan, B. C., Walsh, A. \& Islam, M. S. Ionic transport in hybrid lead iodide perovskite solar cells. Nat. Commun. 6, 8497 (2015).

56 Protesescu, L., Yakunin, S., Bodnarchuk, M. I., Krieg, F., Caputo, R., Hendon, C. H., Yang, R. X., Walsh, A. \& Kovalenko, M. V. Nanocrystals of cesium lead halide perovskites $\left(\mathrm{CsPbX}_{3}, \mathrm{X}=\mathrm{Cl}, \mathrm{Br}\right.$, and $\left.\mathrm{I}\right)$ : novel optoelectronic materials showing bright emission with wide color gamut. Nano Lett. 15, 3692-3696 (2015).

57 Park, H., Dan, Y., Seo, K., Yu, Y. J., Duane, P. K., Wober, M. \& Crozier, K. B. Filter-free image sensor pixels comprising silicon nanowires with selective color absorption. Nano Lett. 14, 1804-1809 (2014).

58 le Coarer, E., Blaize, S., Benech, P., Stefanon, I., Morand, A., Lerondel, G., Leblond, G., Kern, P., Fedeli, J. M. \& Royer, P. Wavelength-scale stationary-wave integrated Fourier-transform spectrometry. Nat. Photonics 1, 473-478 (2007).

59 Du, S., Li, G., Cao, X., Wang, Y., Lu, H., Zhang, S., Liu, C. \& Zhou, H. Oxide semiconductor phototransistor with organolead trihalide perovskite light absorber. Adv. Electron. Mater. 3, 1600325-1600326 (2017).

60 Gunturk, B. K., Glotzbach, J., Altunbasak, Y., Schafer, R. W. \& Mersereau, R. M. Demosaicking: color filter array interpolation. IEEE Signal Process. Mag. 22, 44-54 (2005).

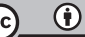

This work is licensed under a Creative Commons Attribution 4.0 International License. The images or other third party material in this article are included in the article's Creative Commons license, unless indicated otherwise in the credit line; if the material is not included under the Creative Commons license, users will need to obtain permission from the license holder to reproduce the material. To view a copy of this license, visit http:// creativecommons.org/licenses/by/4.0/

(C) The Author(s) 2017

Supplementary Information accompanies the paper on the NPG Asia Materials website (http://www.nature.com/am) 